\title{
Efficiency of photoprotection in microphytobenthos: role of vertical migration and the xanthophyll cycle against photoinhibition
}

\author{
João Serôdio ${ }^{1,2, *}$, João Ezequiel ${ }^{1}$, Alexandre Barnett ${ }^{2}$, Jean-Luc Mouget $^{3}$, \\ Vona Méléder $^{2,4}$, Martin Laviale ${ }^{1,4}$, Johann Lavaud ${ }^{2}$ \\ ${ }^{1}$ Departamento de Biologia and CESAM (Centro de Estudos do Ambiente e do Mar), Universidade de Aveiro, \\ Campus de Santiago, 3810-193 Aveiro, Portugal \\ ${ }^{2}$ UMR 7266 'LIENSs', CNRS-University of La Rochelle, Institute for Coastal and Environmental Research (ILE), \\ 2 Rue Olympe de Gouges, 17000 La Rochelle, France \\ ${ }^{3}$ Mer Molécules Santé (MMS) EA 2160, Université du Maine, Av. O. Messiaen, 72085 Le Mans Cedex 9, France \\ ${ }^{4}$ Mer Molécules Santé (MMS) EA 2160, Université de Nantes, BP 92 208, 44322 Nantes Cedex 3, France
}

\begin{abstract}
The capacity of microphytobenthos to withstand the variable and extreme conditions of the intertidal environment, prone to cause photoinhibition, has been attributed to particularly efficient photoprotection. However, little is known regarding the capacity of this protection against photoinhibition or the mechanisms responsible for it. The present study quantified the photoprotective capacity and the extent of photoinhibition under excess light, estimated the contribution of vertical migration and the xanthophyll cycle to overall photoprotection, and evaluated the effects of photoacclimation. A new experimental protocol combined (1) chlorophyll fluorescence imaging, for the simultaneous measurement of replicates and experimental treatments, (2) specific inhibitors for vertical migration and for the xanthophyll cycle, to quantify the relative contribution of each process, and (3) recovery kinetics analysis of photosynthetic activity during light stress-recovery experiments, to distinguish rapidly reversible photochemical down-regulation from photoinhibition. The results show a high photoprotective capacity in 2 study periods, May and October, with photoinhibition rates below $20 \%$. A clear change in photoacclimation state was observed, with acclimation to lower irradiances in autumn associated with higher susceptibility to photoinhibition. In May, vertical migration and the xanthophyll cycle provided comparable protection against photoinhibition; in October, the former predominated. The sum of their contributions was $\sim 20 \%$ in both months, suggesting that other processes also contribute to photoprotection.
\end{abstract}

KEY WORDS: Microphytobenthos - Photoinhibition - Photoprotection - Xanthophyll cycle · Vertical migration $\cdot$ Non-photochemical quenching $\cdot$ Chlorophyll fluorescence $\cdot$ Diatoms

\section{INTRODUCTION}

Benthic microalgae inhibiting estuarine intertidal flats are exposed to extreme and highly variable environmental conditions. Particularly during low tide, the sedimentary environment is characterized by exposure to high levels of solar irradiance (Serôdio \&
Catarino 1999) - including UV radiation (Waring et al. 2007, Mouget et al. 2008) - extreme temperatures and salinities (Brotas et al. 2003, Rijstenbil 2005), intense rates of desiccation (Coelho et al. 2009), supersaturated oxygen concentrations (Chevalier et al. 2010), and nutrient and carbon depletion (Miles \& Sundbäck 2000, Cook \& Røy 2006). Being potentially 
damaging to the photosynthetic apparatus when acting individually, the combined effects of all of these factors likely coalesce in the photoinhibition of photosynthesis of benthic microalgae. Of particular importance is the exposure to direct sunlight, which can result in excessive reductant pressure and in the formation of intracellular reactive oxygen species (ROS; Roncarati et al. 2008, Waring et al. 2010). High levels of ROS cause the permanent inactivation of photosystem II (PSII) protein D1, negatively impacting photosynthetic yield and primary productivity (Nishiyama et al. 2006).

Despite these harsh conditions, microphytobenthos of intertidal flats typically exhibit high growth rates, forming dense and diverse sedimentary biofilms, and are recognized as a major contributor to ecosystemlevel carbon fixation and primary productivity (Underwood \& Kromkamp 1999). Furthermore, an apparent lack of photoinhibition in microphytobenthic biofilms has been repeatedly reported (Blanchard \& Cariou-LeGall 1994, Kromkamp et al. 1998, Underwood 2002, Blanchard et al. 2004, Underwood et al. 2005, Van Leeuwe et al. 2008). This success in coping with high light stress may be explained by the combined operation of 2 processes, the xanthophyll cycle and vertical migration, which could result in overall particularly efficient photoprotection (Serôdio et al. 2008, Perkins et al. 2010b). In diatoms, the group of microalgae that typically dominate in microphytobenthic assemblages, the xanthophyll cycle provides an exceptionally high photoprotective capacity (Lavaud 2007, Brunet \& Lavaud 2010, Goss \& Jakob 2010). This is particularly true for microphytobenthos in situ (Serôdio et al. 2005, Van Leeuwe et al. 2008, Chevalier et al. 2010, Jordan et al. 2010). This high photoprotective capacity may also result from the activation of the xanthophyll cycle in the dark due to chlororespiratory activity, a process considered as potentially advantageous during prolonged periods of darkness (Jakob et al. 2001, Cruz et al. 2011) — a situation common in the sedimentary environment. In contrast, the negative phototactic behavior of benthic diatoms, mostly raphid pennates, under high light has long been interpreted as a form of avoidance of excessive light levels that would otherwise cause pho- toinhibition (Admiraal 1984, Underwood et al. 1999, Consalvey et al. 2004, Waring et al. 2007).

This subject has attracted substantial attention in recent years, particularly centered on the effects of vertical migration on biofilm photophysiology (Consalvey et al. 2004, Jesus et al. 2006, Waring et al. 2007, Mouget et al. 2008, Perkins et al. 2010, Cartaxana et al. 2011), and has been facilitated by the introduction of a diatom motility inhibitor (Cartaxana et al. 2008). However, these studies have been focused on the response of photosynthetic activity during (Waring et al. 2007, Perkins et al. 2010) or shortly after (Mouget et al. 2008) light stress, mostly through in vivo measurements of electron transport rate of PSII (ETR) or non-photochemical quenching (NPQ) of chlorophyll fluorescence (PAM fluorometry, see 'Fluorescence measurements'; Table 1) (Perkins et al. 2010a). Perhaps surprisingly, none of these studies have actually evaluated the efficiency of the photoprotection provided by the xanthophyll cycle and vertical migration or compared their action against photoinhibition in microphytobenthic biofilms. The distinction between photoprotection and photoinhibition processes from chlorophyll fluorescence cannot be inferred from the decrease in ETR or formation of NPQ under excess light but requires an analysis of

Table 1. Definition of terms

\begin{tabular}{|ll|}
\hline Notation & \multicolumn{1}{c|}{ Definition } \\
\hline$\alpha$ & Initial slope of the ETR vs. E curve \\
$a_{1}, b_{1} C$ & Parameters of the Eilers \& Peeters (1988) model \\
DTT & Dithiothreitol \\
$\Delta F / F_{\mathrm{m}}{ }^{\prime}$ & Effective quantum yield of PSII \\
$\mathrm{DD}$ & Diadinoxanthin \\
$\mathrm{DT}$ & Diatoxanthin \\
$\mathrm{DDE}$ & Diadinoxanthin de-epoxidase \\
$E$ & PAR irradiance \\
$E_{50}$ & Irradiance level corresponding to $50 \%$ of NPQ $\mathrm{m}$ in a NPQ vs. \\
& E curve \\
$E_{\mathrm{k}}$ & Photoacclimation parameter of an ETR vs. E curve \\
$\mathrm{ETR}$ & PSII electron transport rate \\
$\mathrm{ETR}$ & Maximum ETR level in an ETR vs. E curve \\
$F_{0,} F_{\mathrm{m}}$ & Minimum and maximum fluorescence of a dark-adapted sample \\
$F_{\mathrm{s}} F_{\mathrm{m}}{ }^{\prime}$ & Steady state and maximum fluorescence of a light-adapted sample \\
Lat A & Latrunculin A \\
$n$ & Sigmoidicity coefficient of the NPQ vs. E curve \\
NPQ & Non-photochemical quenching \\
NPQ & Maximum NPQ level in a NPQ vs. E curve \\
PAR & Photosynthetically active radiation \\
PSII & Photosystem II \\
$q_{\mathrm{E}}$ & Energy-dependent quenching \\
$q_{\mathrm{I}}$ & Photoinhibitory quenching \\
$q_{\mathrm{T}}$ & State-transition quenching \\
$t$ & Time during recovery following light stress \\
$\mathrm{XC}$ & Xanthophyll cycle \\
\hline
\end{tabular}


the recovery kinetics of photosynthetic activity following exposure to light stress (Horton \& Hague 1988, Walters \& Horton 1991, Müller et al. 2001). In diatoms, a rapid (within minutes) component of this recovery can be attributed to the reversal of the xanthophyll cycle ( $q_{\mathrm{E}}$, or 'energy-dependent quenching'), while photoinhibitory effects ( $q_{\mathrm{I}}$, or 'photoinhibitory quenching') can be quantified from a second, much slower (within hours) component (Müller et al. 2001, Lavaud 2007). The $q_{\mathrm{T}}$ (state-transition related quenching) component of NPQ recovery, which shows intermediate relaxation kinetics, does not exist in diatoms (Owens 1986). As such, the following questions are mostly unanswered. How efficient are photoprotective processes in preventing photoinhibition in microphytobenthic biofilms? What is the relative contribution of migration and the xanthophyll cycle for overall photoprotection? To what extent does photoinhibition occur in microphytobenthos?

The present study was designed to address these questions, for which a new experimental protocol was designed, based on the combination of (1) chlorophyll fluorescence imaging, to allow the simultaneous measurement of a large number of samples and experimental treatments, (2) the use of specific inhibitors for vertical migration and for the xanthophyll cycle, to quantify the relative contribution of each process to overall photoprotection, and (3) the analysis of the recovery kinetics of photosynthetic activity following light stress, to distinguish down regulation due to the xanthophyll cycle from down regulation due to photoinhibition. This protocol was further used to test the influence of photoacclimation state on photoprotection capacity and susceptibility to photoinhibition in microphytobenthic biofilms inhabiting a temperate intertidal mudflat.

\section{MATERIALS AND METHODS}

\section{Sampling and sample preparation}

Sediment samples were collected in the upper zone ( $500 \mathrm{~m}$ from the shore, ca. $4 \mathrm{~m}$ above the marine chart datum) of an intertidal mudflat in the Baie de l'Aiguillon $\left(46^{\circ} 15.36^{\prime} \mathrm{N}, 1^{\circ} 8.55^{\prime} \mathrm{W}\right)$, France. Samples were collected in late spring (May) and autumn (October) 2010 and were expected to show contrasting photoacclimation states following the seasonal variation in solar radiation (see end of this section). The sampling site is composed of fine muddy sediments $(<63 \mu \mathrm{m})$ where microphytobenthic biofilms are largely dominated by diatoms (Herlory et al. 2004). During low tide, samples of the surface layers of sediment (the top $\sim 1 \mathrm{~cm}$ ) were collected using a spatula. In the laboratory, the sediment was sieved through a $500 \mu \mathrm{m}$ mesh, to remove the mud snails Hydrobia sp. and other meio- and macrofauna, and was thoroughly mixed and spread in $4 \mathrm{~cm}$ deep plastic trays. The sediment was covered with water collected in the sampling site and left undisturbed overnight. During the next morning, at the start of the photoperiod, the slurries were again homogenized, and identical portions of the resulting slurry were transferred to 24well plates using a small spatula, filling the wells completely (ca. $3 \mathrm{ml}$ ). The well plates were exposed to a homogeneous light field provided by 2 LED panels (equal contribution of red, far-red, blue, and white LEDs; FloraLEDs panels, Plant Climatics), delivering a constant irradiance of $70 \mu \mathrm{mol}$ quanta $\mathrm{m}^{-2} \mathrm{~s}^{-1}$ at the sample surface, to induce the upward migration of microalgae and the formation of the biofilm. Daily global solar radiation data were obtained from a Meteo-France weather station located $\sim 9 \mathrm{~km}$ southwest from the sampling site for $2 \mathrm{wk}$ periods preceding the sampling dates, 15-30 May and 5-20 October 2010.

\section{Fluorescence measurements}

Chlorophyll fluorescence was measured using an imaging-PAM fluorometer (Maxi-PAM M-series, Walz). The measuring area of the fluorometer covered each entire well plate, so that up to a total of 24 sediment samples could be monitored simultaneously. All experiments were carried out after biofilm formation. This was determined by measuring the fluorescence level $F_{\mathrm{s}}$ taken as a proxy for surface microalgal biomass, in a replicated set of samples exposed to constant low light of $55 \mu \mathrm{mol}$ quanta $\mathrm{m}^{-2} \mathrm{~s}^{-1}$. Experiments were started after $F_{\mathrm{s}}$ reached a plateau following the initial rise after the onset of the light period, which typically took 2 to $3 \mathrm{~h}$ of low light exposure. For each sample, the fluorescence signal was calculated by averaging the values of all pixels included in an area of ca. $63.6 \mathrm{~mm}^{2}$ (area of interest), which corresponded to ca. 1500 pixels, centered inside each well. This area is smaller than the total area of each well $\left(95.0 \mathrm{~mm}^{2}\right)$, the difference being due to the exclusion of the edge of each sample, often not representative of the rest of the biofilm. To minimize sample heating during prolonged exposure to high light, the experiments were carried out in a temperature-controlled room at $20^{\circ} \mathrm{C}$, and the fluorometer Perspex hood was maintained open at all times. 


\section{Photoacclimation: light-response curves}

The photoacclimation state of the samples was characterized by measuring the light-response curves of ETR and NPQ in the 2 sampling periods. Light-response curves were generated by sequentially exposing the samples to 7 levels of actinic light, up to $700 \mathrm{mmol}$ quanta $\mathrm{m}^{-2} \mathrm{~s}^{-1}$. Samples were exposed to each light level for $3 \mathrm{~min}$ (a period previously confirmed to allow for reaching a steady-state), after which a saturation pulse was applied and fluorescence levels $F_{\mathrm{s}}$ and $F_{\mathrm{m}}{ }^{\prime}$ were recorded. A total of 6 replicated measurements (on 6 different wells) were made for each light level. For each irradiance level, $E$, the relative ETR was calculated from the product of $E$ and the PSII effective quantum yield, $\Delta F / F_{\mathrm{m}}{ }^{\prime}$ (Genty et al. 1989):

$$
\mathrm{ETR}=E \frac{F_{\mathrm{m}}{ }^{\prime}-F_{\mathrm{s}}}{F_{\mathrm{m}}{ }^{\prime}}
$$

ETR vs. E curves were quantitatively described by fitting the model of Eilers \& Peeters (1988) and by estimating the parameters $\alpha$ (the initial slope of the curve), ETR $\mathrm{ET}_{\mathrm{m}}$ (maximum ETR), and $E_{\mathrm{k}}$ (the lightsaturation, or photoacclimation, parameter):

$$
\operatorname{ETR}(E)=\frac{E}{a E^{2}+b E+c}
$$

where

$$
\alpha=\frac{1}{c}, \operatorname{ETR}_{\mathrm{m}}=\frac{1}{b+\sqrt{a c}} \text { and } E_{\mathrm{k}}=\frac{C}{b+\sqrt{a c}}
$$

Due to the unavoidable confounding effects of vertical migration on the measurement of $F_{\mathrm{m}}$, NPQ was calculated using the adapted index based on the relative difference between the maximum fluorescence measured during the construction of the light curve, $F_{\mathrm{m}, \mathrm{m}}{ }^{\prime}$ and upon exposure to light, $F_{\mathrm{m}}{ }^{\prime}$ (Serôdio et al. 2005):

$$
\mathrm{NPQ}=\frac{F_{\mathrm{m}, \mathrm{m}}^{\prime}-F_{\mathrm{m}}{ }^{\prime}}{F_{\mathrm{m}}{ }^{\prime}}
$$

NPQ vs. $E$ curves were described by fitting the model of Serôdio \& Lavaud (2011) and by estimating the parameters $\mathrm{NPQ}_{\mathrm{m}}$ (maximum NPQ), $E_{50}$ (irradiance corresponding to half of $\mathrm{NPQ}_{\mathrm{m}}$ ), and $n$ (sigmoidicity parameter):

$$
\mathrm{NPQ}(E)=\mathrm{NPQ}_{\mathrm{m}} \frac{E^{n}}{E_{50}^{n}+E^{n}}
$$

These models were fitted using a procedure written in MS Visual Basic and based on MS Excel Solver. Model parameters were estimated iteratively by minimizing a least-squares function, forward differencing, and the default quasi-Newton search method. The model was fitted to individual lightresponse curves. Estimates of model parameters were compared using a Student's $t$-test. The standard errors of the parameter estimates were calculated following Ritchie (2008).

\section{Photoprotection vs. photoinhibition: light stress-recovery experiments}

The photoprotection capacity of microphytobenthic biofilms was estimated by quantifying the recovery of $\Delta F / F_{\mathrm{m}}$ ' following a prolonged exposure to supersaturating irradiance. Three replicates were sequentially exposed to (1) a low light level of $55 \mu \mathrm{mol}$ quanta $\mathrm{m}^{-2} \mathrm{~s}^{-1}$, for a minimum of $15 \mathrm{~min}$, to ensure full light-activation of the photosynthetic apparatus and to determine pre-stress reference levels of $\Delta F / F_{\mathrm{m}}{ }^{\prime}$; (2) a supersaturating light level of $1200 \mu \mathrm{mol}$ quanta $\mathrm{m}^{-2} \mathrm{~s}^{-1}$ for $3 \mathrm{~h}$, to potentially induce photoinhibitory effects; and (3) low light (55 $\mu \mathrm{mol}$ quanta $\mathrm{m}^{-2}$ $\mathrm{s}^{-1}$ ) for a minimum of $15 \mathrm{~min}$ to record the recovery kinetics. During the whole experiment, $\Delta F / F_{\mathrm{m}}{ }^{\prime}$ was measured by applying saturating pulses every $90 \mathrm{~s}$. The recovery of $\Delta F / F_{\mathrm{m}}$ ' upon the return to low light conditions was described by fitting an exponential function, adapted from a first-order kinetics model derived for describing the kinetics of NPQ (Olaizola \& Yamamoto 1994, Serôdio et al. 2005):

$\Delta F / F_{\mathrm{m}}^{\prime}(t)=\Delta F / F_{\mathrm{m}, \text { rec }}^{\prime}+\left[\Delta F / F_{\mathrm{m}}^{\prime}(0)-\Delta F / F_{\mathrm{m}, \text { rec }}^{\prime}\right] \mathrm{e}^{-k t}$

where $t$ is the time during recovery, $\Delta F / F_{\mathrm{m}}{ }^{\prime}(0)$ and $\Delta F / F_{\mathrm{m}}{ }^{\prime}$,rec represent the PSII quantum yield levels at the start of the recovery period and after full recovery (associated to $q_{\mathrm{E}}$ ), and $k$ is the rate constant of the $\Delta F / F_{\mathrm{m}}{ }^{\prime}$ recovery. The values of $\Delta F / F_{\mathrm{m}}$ ' estimated by the model for $t=10.5 \mathrm{~min}$, expressed as a percentage of the pre-stress levels, were used for estimating the effective photoprotective capacity of the biofilm. The remaining relative difference between pre- and post-stress levels of $\Delta F / F_{\mathrm{m}}$ ' was used as an estimate of the photoinhibitory effects imposed by excess light (defined as supersaturating irradiance levels, above $E_{\mathrm{k}}$ )

The photoprotective roles of vertical migration and of the xanthophyll cycle were studied by applying specific inhibitors of the 2 processes. Vertical migration was inhibited by the diatom motility inhibitor latrunculin (Lat) A, shown to effectively inhibit cell motility without causing appreciable effects on the 
photosynthetic activity (Cartaxana et al. 2008). To inhibit the activity of the xanthophyll cycle, the inhibitor of the diadinoxanthin de-epoxidase (DDE) dithiothreitol (DTT) was used. DTT is commonly used to inhibit the conversion of the pigment diadinoxanthin (DD) into the photoprotective form diatoxanthin (DT) (Lavaud et al. 2002a). DTT was applied in combination with Lat A to ensure that the cells with the xanthophyll cycle inhibited remained exposed to high light.

The contribution of vertical migration to the overall photoprotection capacity of the biofilm was estimated by the difference between the levels of $\Delta F / F_{\mathrm{m}}{ }^{\prime}$ recovery in control (free moving cells) and Lat Atreated (vertical migration inhibited) samples. The contribution of the xanthophyll cycle was estimated by comparing the levels of $\Delta F / F_{\mathrm{m}}$ ' recovery in the samples treated with Lat A (only vertical migration inhibited) and in those treated with both Lat A and DTT (both vertical migration and the xanthophyll cycle inhibited). The inhibitor solutions were added after the biofilm was fully formed in a total of $200 \mu \mathrm{l}$ for both the Lat A and the Lat A + DTT solutions. The same volume of filtered seawater was added to the control samples. The solutions were added carefully to minimize biofilm disturbance by pipetting small volumes onto the sediment surface. A minimum of 30 min was given for the inhibitors to diffuse and for the biofilms to stabilize before measurements were started.

\section{Inhibitor preparation and effective dosage}

Solutions of Lat A of different concentrations, ranging from 5 to $15 \mu \mathrm{M}$, were prepared from a concentrated solution $(1 \mathrm{mM})$ prepared from dissolving purified Lat A (Sigma-Aldrich) in dimethylsulfoxide. The minimum effective dosage of Lat $A$ to induce inhibition of vertical migration was determined following Cartaxana \& Serôdio (2008). Samples treated with different concentrations of Lat A (final volume $200 \mu \mathrm{l}$ ) were darkened close to the time expected for tidal flood, known to induce a rapid downward migration. The degree of migration inhibition was estimated from the decrease in surface biomass following darkening, as estimated from the dark-adapted fluorescence level, $F_{0}$. Three replicate samples were tested for each Lat A concentration.

DTT (BDH-Prolabo) was prepared fresh as in Lavaud et al. (2002a). A stock solution of $300 \mathrm{mM}$ (in ethanol) was diluted in filtered seawater to prepare working solutions of concentrations ranging from 3.3 to $15 \mathrm{mM}$. The minimum effective dosage of DTT was determined by measuring NPQ development upon exposure to $400 \mu \mathrm{mol}$ quanta $\mathrm{m}^{-2} \mathrm{~s}^{-1}$ for $30 \mathrm{~min}$ in samples treated with increasing concentration of DTT (final volume $200 \mu \mathrm{l}$ ). Three replicated samples were tested for each DTT concentration. For the light stress experiments, samples were treated with $200 \mu \mathrm{l}$ of a combined solution of Lat A and DTT, prepared using the concentration of each inhibitor determined from the effective dosage tests (see 'Results').

\section{Taxonomic composition}

In one of the trays, microalgae were collected by covering the sediment with 2 layers of a $100 \mu \mathrm{m}$ mesh. The trays were exposed to low indirect light from a north facing window $(<200 \mu$ mol quanta $\mathrm{m}^{-2} \mathrm{~s}^{-1}$ ) during the day following the sampling. The upper mesh was removed at the time of middle emersion period, and it was washed with filtered $(0.2 \mu \mathrm{m})$ natural seawater. The samples were fixed in Lugol's solution and preserved at $4{ }^{\circ} \mathrm{C}$ until analysis. Diatom species were identified and counted using definitive mounts in Naphrax after cleaning the cells by cremation $\left(2 \mathrm{~h}, 450^{\circ} \mathrm{C}\right)$ (Méléder et al. 2007). Taxonomic determination was performed by microscope on the basis of morphological criteria (Ribeiro 2010). A total of ca. 300 diatom frustules were counted to determine specific abundances.

\section{RESULTS}

\section{Photoacclimation}

Significant differences were found between the light response of ETR measured in May and October. In comparison with the ETR vs. E curves measured in May, the ones measured in October presented significantly higher values of $\alpha(26.7 \%, t$-test, $\mathrm{p}<0.001)$ and lower values of $\operatorname{ETR}_{\mathrm{m}}(-41.5 \%, t$-test, $\mathrm{p}<0.001)$ (Fig. 1A). As a consequence, the photoacclimation parameter $E_{\mathrm{k}}$ was significantly lower in October than in May $(-53.5 \%$; $t$-test, $\mathrm{p}<0.001)$. Regarding $N P Q$, significant differences were found between the lightresponse curves measured in the 2 periods (Fig. 1B). The NPQ vs. E curves measured in May reached lower levels within the range of applied irradiances (on average, 2.19 and 3.25 at $700 \mu \mathrm{mol}$ quanta $\mathrm{m}^{-2}$ $\mathrm{s}^{-1}$, in May and October, respectively), although the values of $\mathrm{NPQ}_{\mathrm{m}}$ were not significantly different $(t-$ test, $\mathrm{p}=0.425$ ). The light-response curves were more 

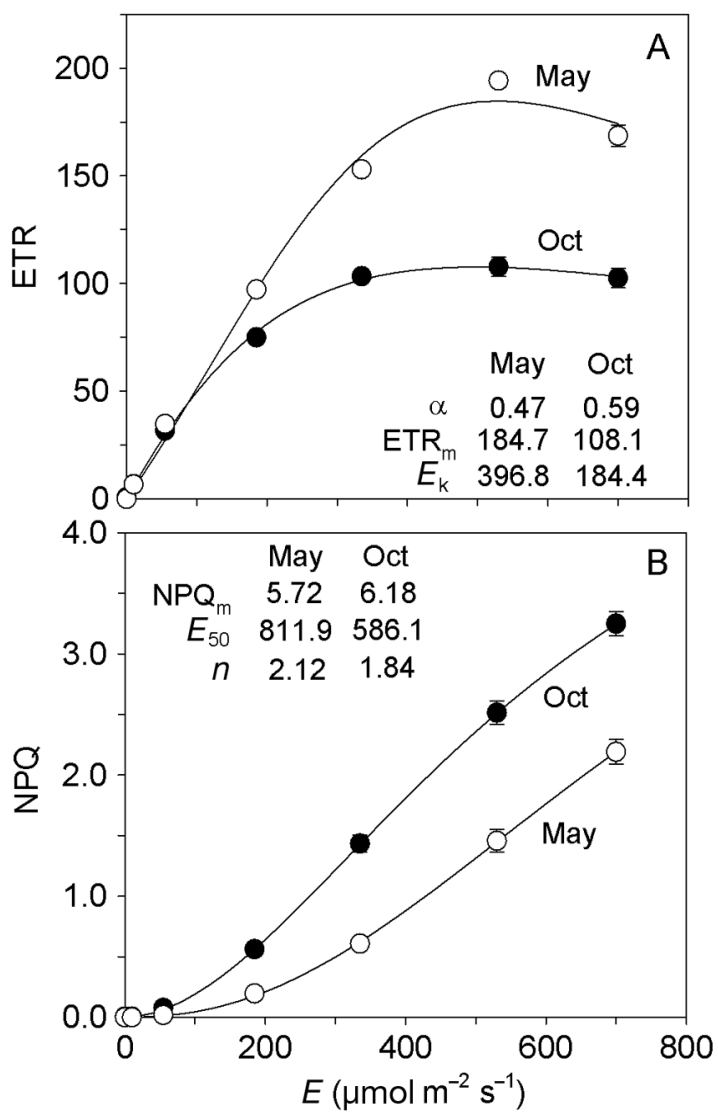

Fig. 1. Light-response curves of (A) PSII electron transport rate (ETR) and (B) non-photochemical quenching (NPQ) measured in May and October 2010. Mean of 6 replicates. Vertical bars are 1 SE. Numbers represent the mean values of model parameters estimated for light-response curves measured for each individual sample. See Table 1 for definition of parameters

sigmoid in May than in October ( $t$-test, $\mathrm{p}=0.001)$, the largest differences being found regarding the light level required for induction of NPQ, indicated by the parameter $E_{50}$, which was significantly lower in October than in May $(-38.5 \%$; $t$-test, $\mathrm{p}=0.003)$.

The light conditions in the region of the sampling area varied greatly between the 2 wk periods preceding the sampling periods, with global solar radiation reaching a daily average of $2369 \mathrm{~J} \mathrm{~cm}^{-2}$ in May, more than double the value observed in October, $1008 \mathrm{~J} \mathrm{~cm}^{-2}$.

\section{Inhibitor dosage}

Vertical migration was strongly inhibited for most of the Lat A concentrations tested, with an inhibition level $>75 \%$ being obtained with only $5 \mu \mathrm{M}$ (Fig. 2). The inhibitory response to the increase in Lat A con- centration presented a clear saturation-like pattern, with the increase from 10 to $15 \mu \mathrm{M}$ resulting in an increase in inhibition of only $8.5 \%$. Considering that $10 \mu \mathrm{M}$ was enough to inhibit vertical migration by $>90 \%$ and the small increase obtained by applying the higher concentrations, solutions of $10 \mu \mathrm{M}$ Lat A were used in all experiments.

The response of NPQ to the increase in DTT also showed a saturation-like pattern, characterized by a strong decrease for concentrations up to $5 \mathrm{mM}$ and a virtually constancy for concentrations above this value (NPQ decreased by $19 \%$ between 5 and $15 \mathrm{mM}$; Fig. 3). However, even when the highest DTT concentration was applied, NPQ was never completely eliminated, remaining above 1.0. In all further experiments, a concentration of DTT of $10 \mathrm{mM}$ was used.

\section{Light stress exposure and recovery}

Fig. 4 exemplifies the variation of $\Delta F / F_{\mathrm{m}}$ ' during a light stress-recovery experiment. On the control samples, exposure to excess light induced an immediate and marked decrease in $\Delta F / F_{\mathrm{m}}$ ' from ca. 0.63 to values slightly below 0.1 (Fig. 4 ). $\Delta F / F_{\mathrm{m}}$ ' further decreased to values close to zero during the first $15 \mathrm{~min}$ of exposure, after which it gradually recovered, stabilizing at values around 0.1 after 90 min and until the end of the high light period. On inhibitor-treated samples, $\Delta F / F_{\mathrm{m}}{ }^{\prime}$ also decreased to values close to zero upon the start of high light exposure but, in contrast to control samples, never showed any appreciable recovery, remaining below 0.05 (Fig. 4). How-

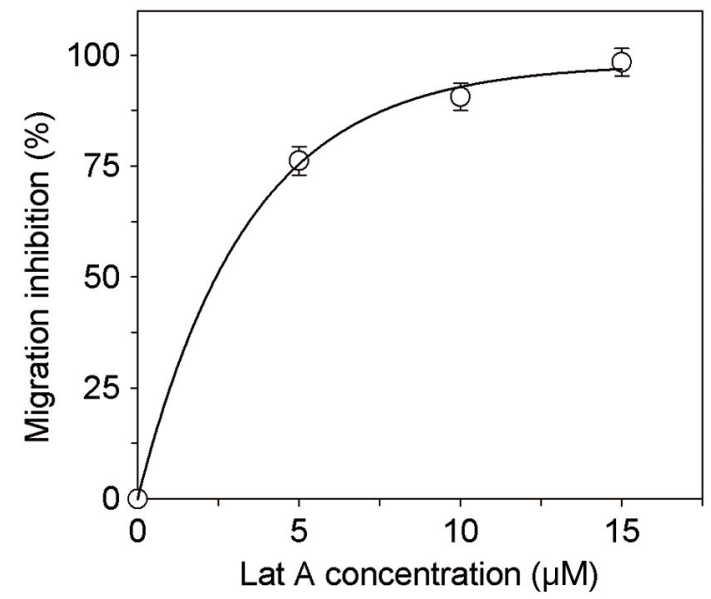

Fig. 2. Variation of migration inhibition with the concentration of added latrunculin A (Lat A) solution. Mean of 3 replicates. Vertical bars are 1 SE. Line represents the fit of the exponential decay model 


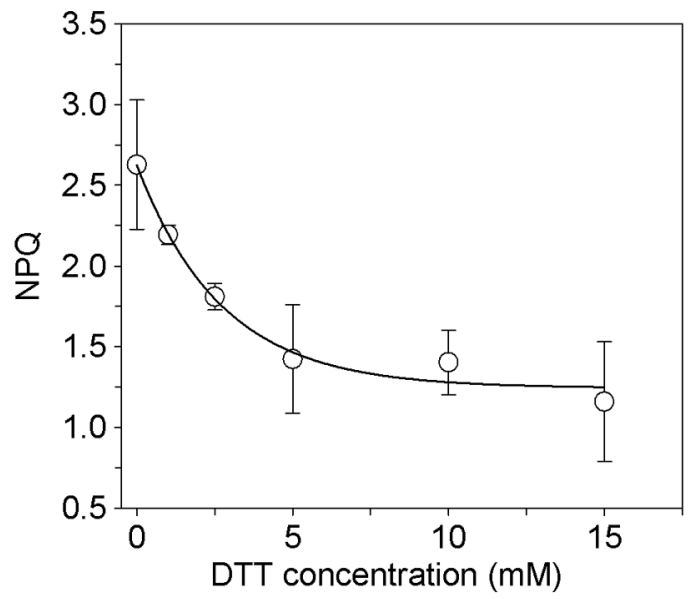

Fig. 3. Inhibition of non-photochemical quenching (NPQ) as a function of concentration of added dithiothreitol (DTT) solution. NPQ induced upon exposure to $400 \mu \mathrm{mol}$ quanta $\mathrm{m}^{-2} \mathrm{~s}^{-1}$. Mean of 3 replicates. Vertical bars are 1 SE. Line represents the fit of the exponential decay model

ever, $\Delta F / F_{\mathrm{m}}$ ' levels were usually higher in Lat Atreated samples than in those treated with both inhibitors (Figs. 4 \& 5). Following the transition to low light, a clear recovery response was observed for all samples, with $\Delta F / F_{\mathrm{m}}{ }^{\prime}$ reaching in all cases over $60 \%$ of initial values after $15 \mathrm{~min}$. Treatment with Lat A effectively inhibited vertical migration during the whole experiment, as indicated by the small variation in $F_{\mathrm{s}}$ in Lat A-treated samples (on average, $-12.1 \%$ for samples treated with Lat A and Lat A + DTT) compared to the controls $(-43.5 \%$; Fig. 6$)$. The effects of inhibitors were particularly evident during recovery under low light, during which $\Delta F / F_{\mathrm{m}}$ ' followed the negative exponential pattern described by Eq. (6), the fit of which was very good in all cases $\left(\mathrm{r}^{2}>0.91\right.$; Fig. 7). Control samples recovered more rapidly than those treated with inhibitors, so that $3 \mathrm{~min}$ after the return to low light, the $\Delta F / F_{\mathrm{m}}$ ' of non-inhibited samples was over $70 \%$ and $60 \%$ higher than on samples treated with Lat A in May and October, respectively. In both periods, these differences were gradually reduced during exposure to low light, but after $10.5 \mathrm{~min}$, the percentage of recovery was significantly different among treatments and sampling periods (2-way ANOVA, $\mathrm{p}<0.001$ for both factors). In both May and October, the recovery of $\Delta F / F_{\mathrm{m}}{ }^{\prime}$ was higher in the controls than in the Lat A-treated

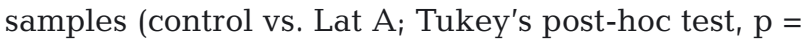
0.043 and $p=0.010$, respectively), which was in turn higher than in samples treated with Lat A and DTT (Lat A vs. Lat A + DTT; Tukey's post-hoc test, p = 0.042 and $p=0.030$, respectively). The percentage of recovery was in all cases significantly higher in May than in October (Tukey's post-hoc test, p < 0.05), with the exception of samples treated with both inhibitors (Tukey's post-hoc test, $\mathrm{p}=0.107$ ).

\section{Photoprotection efficiency and extent of photoinhibition}

Depending on the species, the full recovery of the xanthophyll cycle after a transition from high to low light generally occurs after 6 to 15 min (Goss et al.

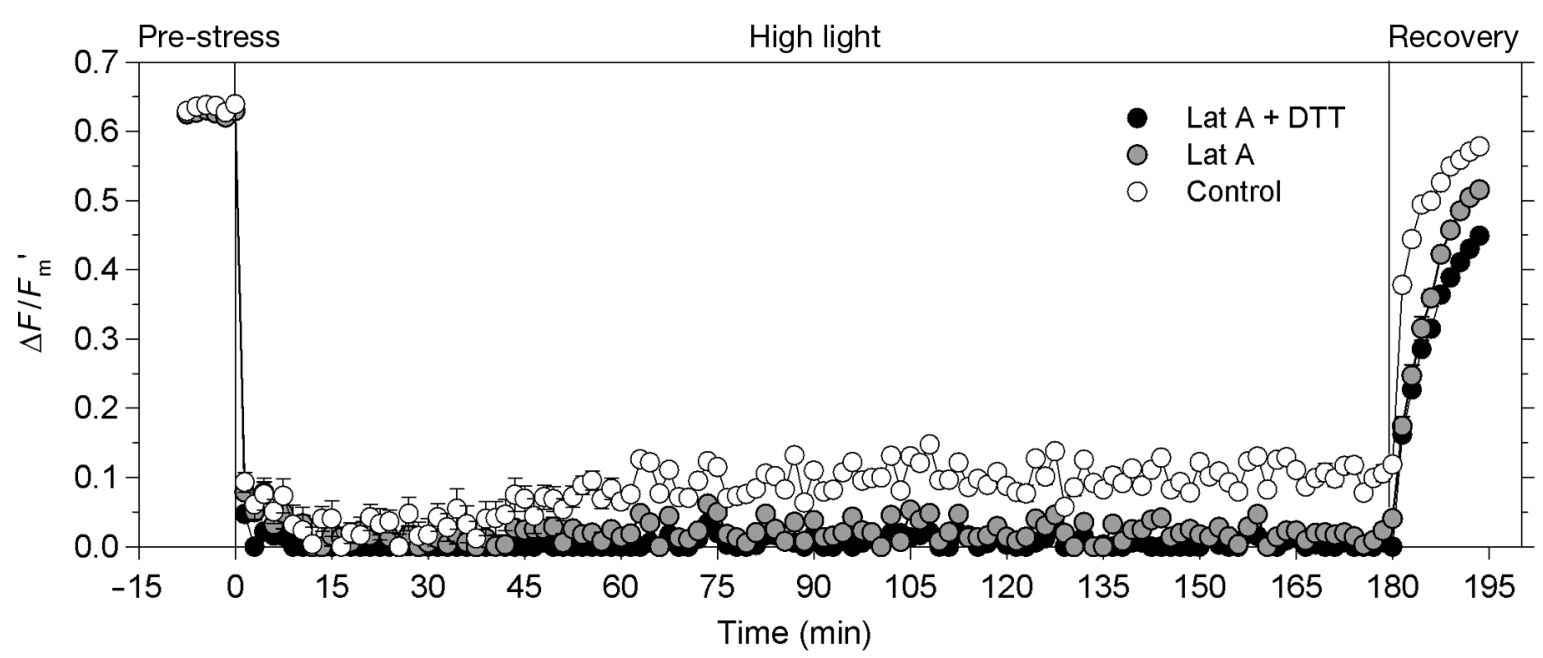

Fig. 4. Light stress-recovery experiment. Variation of PSII quantum yield, $\Delta F / F_{\mathrm{m}}{ }^{\prime}$, during sequential exposure to low light (prestress, $55 \mu \mathrm{mol}$ quanta $\mathrm{m}^{-2} \mathrm{~s}^{-1}$ ), light stress under high light (high light, $1200 \mu \mathrm{mol}$ quanta $\mathrm{m}^{-2} \mathrm{~s}^{-1}, 180 \mathrm{~min}$ ) and recovery under low light (recovery, $55 \mu \mathrm{mol}$ quanta $\mathrm{m}^{-2} \mathrm{~s}^{-1}, 10.5 \mathrm{~min}$ ) for controls and for samples treated with migration inhibitor latrunculin A (Lat A) and with migration and xanthophyll cycle inhibitors (Lat A + dithiothreitol [DTT]), collected in May 2010. Mean of 


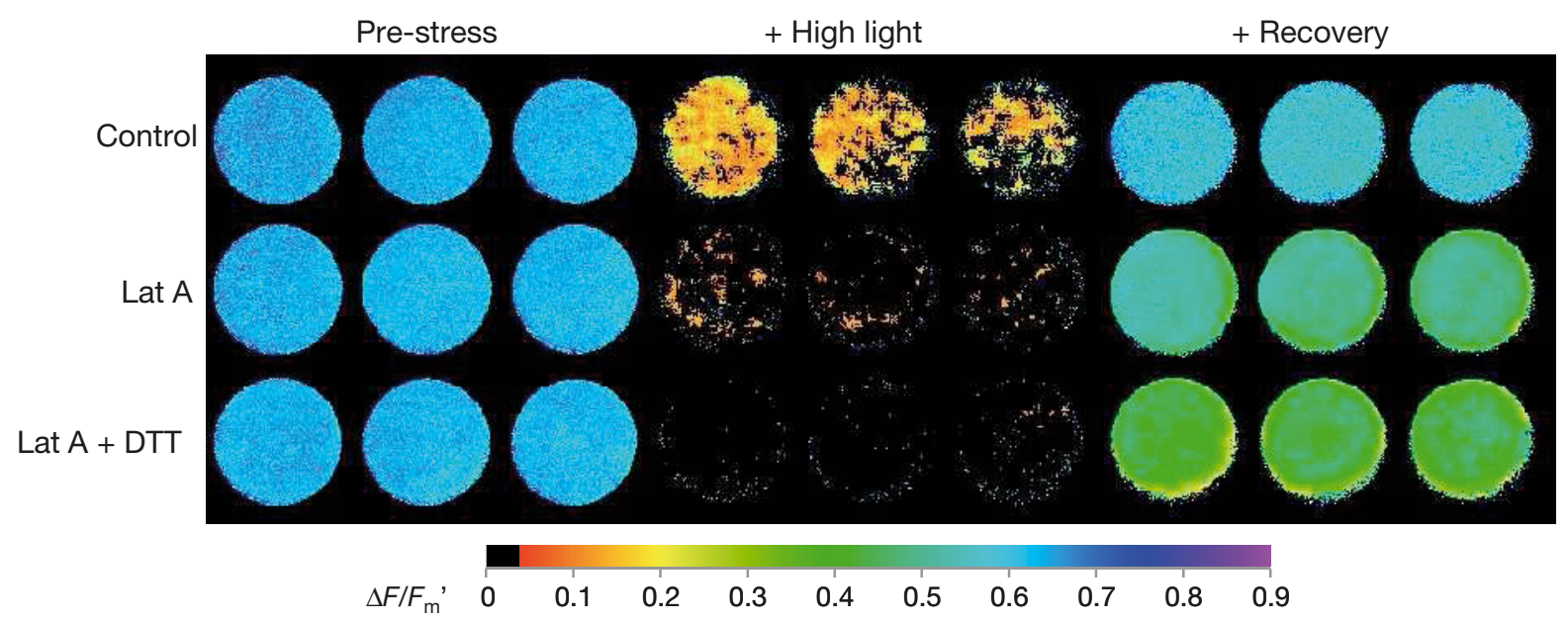

Fig. 5. PSII quantum yield, $\Delta F / F_{\mathrm{m}}$ ' (false color scale), as measured in the sediment samples used in the light stress experiment described in Fig. 4 at the end of first low light exposure (pre-stress, $55 \mu \mathrm{mol}$ quanta $\mathrm{m}^{-2} \mathrm{~s}^{-1}$ ), at the end of high light exposure (high light, $1200 \mu \mathrm{mol}$ quanta $\mathrm{m}^{-2} \mathrm{~s}^{-1}, 180 \mathrm{~min}$ ) and following recovery under low light (recovery, $55 \mu \mathrm{mol}$ quanta $\left.\mathrm{m}^{-2} \mathrm{~s}^{-1}, 10.5 \mathrm{~min}\right)$. Three replicated areas of interest for each treatment

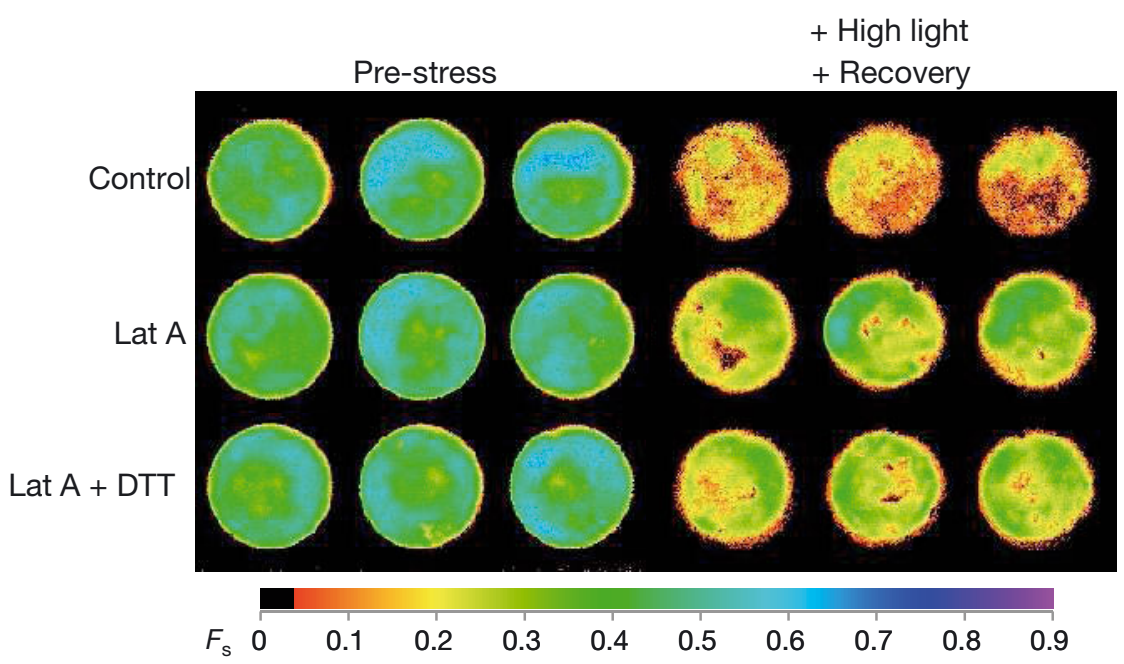

Fig. 6. Fluorescence level $F_{\mathrm{s}}$ (false color scale) as measured in the sediment samples used in the light stress experiment described in Fig. 4 at the end of first low light exposure (pre-stress, $55 \mu \mathrm{mol}$ quanta $\mathrm{m}^{-2} \mathrm{~s}^{-1}$ ) and after recovery following end of high light exposure (high light, $1200 \mu \mathrm{mol}$ quanta $\mathrm{m}^{-2} \mathrm{~s}^{-1}$,

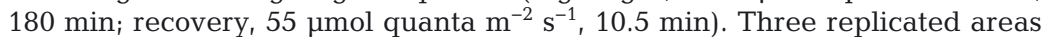
of interest for each treatment

2006, B. Lepetit \& J. Lavaud pers. obs.). Considering the intermediate period of $10.5 \mathrm{~min}$, the recovery of $\Delta F / F_{\mathrm{m}}{ }^{\prime}$ at this time was used as an estimate of the photoprotection capacity and to calculate the extent of photoinhibition that occurred. The results indicate that the microphytobenthic biofilms had a large photoprotective capacity in both periods, with a correspondingly low percentage of photoinhibition below $25 \%$, although higher in May than in October (87.7 and $78.0 \%$; Fig. 8, Table 2). From the reduction in the photoprotection capacity measured in samples treated with inhibitors, the contribution of vertical migration and of the xanthophyll cycle to overall photoprotection were estimated to reach a combined value only slightly above $20 \%$ (Table 2). While in May the 2 processes had a comparable contribution to photoprotection, the relative importance of the xanthophyll cycle was reduced to $7.2 \%$ in October.

\section{Taxonomic composition}

In both sampling periods, the microphytobenthic assemblages were dominated by long biraphid diatoms (length > $30 \mu \mathrm{m}$ ). In May, the assemblages were mainly dominated by Navicula cf. spartinentensis $(61 \%, \mathrm{n}=$ 350). Staurophora salina represented $<20 \%$ of the assemblages, but this species was 2 -fold longer than $N$. cf. spartinentensis (22 and $44 \mu \mathrm{m}$ long, respectively). In October, the assemblages were codominated by Plagiotropis seriata $(22 \%, \mathrm{n}=335)$ and Staurophora salina $(19 \%)$; the size of $P$. seriata (190 $\mu \mathrm{m}$ long) was 4 -fold greater than that of $S$. salina (44 $\mu \mathrm{m}$ long), strengthening its dominance in terms of biovolume. A third species, Pleurosigma strigosum (300 $\mu \mathrm{m}$ length), represented $<10 \%$ of the assemblage abundance. 


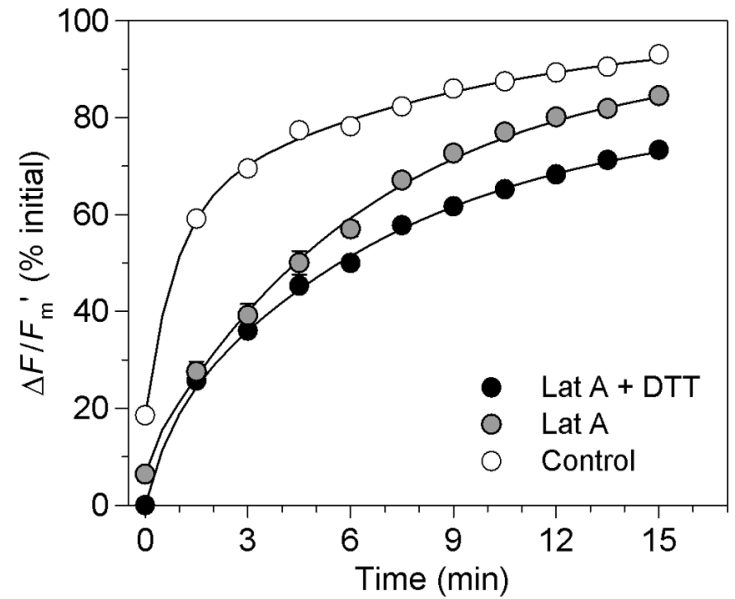

Fig. 7. Recovery of PSII quantum yield, $\Delta F / F_{\mathrm{m}}{ }^{\prime}$, during relaxation following light stress for control samples and for samples treated with migration inhibitor latrunculin A (Lat A) and with migration and xanthophyll cycle inhibitors (Lat A + dithiothreitol [DTT]). Lines represent the exponential model described by Eq. (6) fitted to average $\Delta F / F_{\mathrm{m}}{ }^{\prime}$ values. Detail of Fig. 4. Vertical bars are $1 \mathrm{SE}$

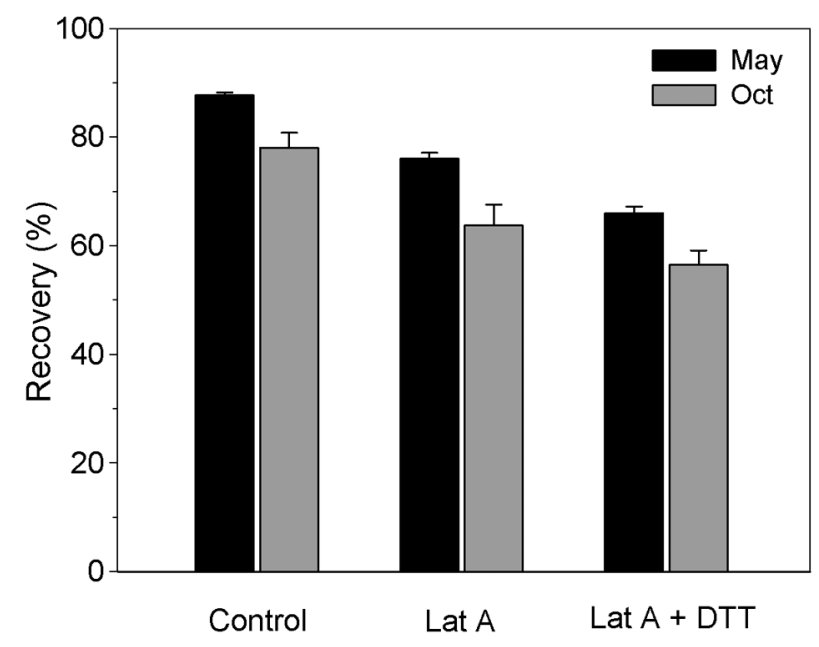

Fig. 8. Efficiency of photoprotection, as percentage of recovery after $10.5 \mathrm{~min}$ low light following high light exposure, in May and October for controls and inhibitor-treated samples. Mean of 3 replicates. Vertical bars are $1 \mathrm{SE}$

\section{DISCUSSION \\ Photoacclimation and susceptibility to photoinhibition}

Compared to those from May, samples collected in October appeared acclimated to lower light levels, showing the pattern typically associated to 'shadeacclimation': a combination of higher values of $\alpha$ and lower values of $\mathrm{ETR}_{\mathrm{m}}$, resulting in lower values of $E_{\mathrm{k}}$, usually taken as an indication of photosynthesis saturating at lower irradiances. This change in photoacclimation state between May and October was consistent with that expected from the observed seasonal change in solar light conditions preceding the 2 sampling periods (global solar radiation $>2$-fold higher in May than in October). These results also are in agreement with previous observations on the seasonal variability of microphytobenthos photosynthetic performance, showing patterns of acclimation to higher light levels during spring/summer and to lower levels in autumn/winter (Blanchard et al. 1997, Migné et al. 2004, Serôdio et al. 2006). In this context, seasonal variation of UV irradiance may have also played a role (Wulff et al. 2008). The results were also consistent with the photoacclimation response of benthic diatoms grown in culture exposed to low- and high-light regimes (Perkins et al. 2006, Schumann et al. 2007, Cruz \& Serôdio 2008). Increases of $\alpha$, such as that observed from May to October, are commonly attributed to an increase in the cellular content of light-harvesting pigments, increasing the fraction of incident light that is intercepted and absorbed for photosynthesis; decreases in $\mathrm{ETR}_{\mathrm{m}}$ are typically associated with the decrease in the activity of the electron transport chain or the Calvin cycle, limiting factors of light-saturated photosynthesis (Henley 1993, MacIntyre et al. 2002, Behrenfeld et al. 2004).

A change in light response was also noticeable regarding NPQ, with the samples collected in October showing NPQ activation starting at lower light

Table 2. Extent of photoinhibition and efficiency of photoprotection (\%), calculated as percentage of $\Delta F / F_{\mathrm{m}}{ }^{\prime}$ recovery after $10.5 \mathrm{~min}$. Relative contributions of vertical migration and of the xanthophyll cycle to overall photoprotection (\%), as calculated from the reduction of the $\Delta F / F_{\mathrm{m}}$ ' recovery in samples treated with latrunculin A (Lat A) and with Lat A and dithiothreitol, respectively, relative to control samples. Means \pm SE of 3 replicates are shown. Numbers within parentheses indicate results obtained when considering 6 and 15 min of recovery, respectively

\begin{tabular}{|lccccc|}
\hline & Photoinhibition & Recovery & Vertical migration & Xanthophyll cycle & Others \\
\hline May & $12.3 \pm 0.55(16.6,11.7)$ & $87.7 \pm 0.55(83.4,88.3)$ & $10.6(24.0,3.6)$ & $10.1(6.4,13.2)$ & $79.3(69.5,83.2)$ \\
October & $22.0 \pm 2.79(33.7,17.0)$ & $78.0 \pm 2.79(66.3,83.0)$ & $14.3(17.0,11.7)$ & $\begin{array}{r}7.2(7.3,5.8) \\
78.5(75.7,82.5)\end{array}$ \\
\hline
\end{tabular}


levels (lower $E_{50}$ ) and higher values of NPQ for most irradiances (higher $\mathrm{NPQ}_{\mathrm{m}}$ ). As with ETR, the observed variation in the NPQ vs. $E$ curves was consistent with that previously reported for microphytobenthos (Serôdio et al. 2006) or for benthic diatoms acclimated to different light regimes (Cruz \& Serôdio 2008).

However, while changes in the light-response of ETR may be interpreted and related to underlying physiological processes in a relatively straightforward manner, the physiological meaning of changes in NPQ levels is more difficult to ascertain. This is because the 2 components of NPQ, $q_{\mathrm{E}}$ (photoprotection) and $q_{\mathrm{I}}$ (photoinhibition), can only be distinguished through the analysis of the recovery kinetics after exposure to high light, but not from NPQ light curves. In the present study, the light stress-recovery experiments allowed the conclusion that the observed change in the NPQ light-response curves was due to a decrease in the $q_{\mathrm{E}}$ component and a concomitant increase in the $q_{\mathrm{I}}$ component. In the absence of information from NPQ recovery kinetics, similar increases in NPQ vs. E curves in autumn/ winter periods have been, perhaps wrongly, interpreted as being due to an increase in photoprotective capacity (Serôdio et al. 2005, 2006).

Furthermore, the results from the light stressrecovery experiments revealed an association between photoacclimation status and photoprotection efficiency, not shown before for these communities. Whatever the cause, the acclimation to high light observed in May was associated with a high photoprotection capacity, while the acclimation to low light observed in October coincided with a loss of photoprotection and a higher susceptibility to photoinhibition.

\section{Photoprotection vs. photoinhibition}

A central finding of the present study is that photoinhibition was in all cases considerably low (ca. $20 \%$ ), indicating photoprotection to be particularly efficient in the studied microphytobenthic biofilms. Despite the general view that these assemblages hardly show any photoinhibition (Blanchard et al. 2004, Waring et al. 2007, Mouget et al. 2008), this process has been shown to occur under in situ conditions (Serôdio et al. 2008). Curiously, the rates of photoinhibition estimated in Serôdio et al. (2008), reaching up to ca. $18 \%$, are similar to the values reported here, despite the fact that the previous values were estimated from hysteresis patterns ob- served during complete periods of low tide exposure. The results of the present study therefore confirm that the photoprotective mechanisms available to benthic diatoms are not completely efficient in preventing some degree of photoinhibitory damage. However, the difficulty in comparing the measured rates of photoinhibition with results published for other habitats or for other estuarine primary producers, such as phytoplankton, seagrasses or macroalgae, should be stressed. Apart from the light history and the species-specific differences, the extent of photoinhibition is directly related to light dosage, determined by light intensity and duration of exposure, both largely variable among the different experimental protocols used in different laboratory and field studies.

A number of unaccounted for factors may have contributed to the measured low values of $q_{\mathrm{I}}$. First, the well-known effect of depth-integration of subsurface fluorescence (Forster \& Kromkamp 2004, Serôdio 2004). This effect is caused by the fact that only the cells at or near the surface are actually exposed to the high light levels measured incident to the sediment surface, while the fluorescence signal measured above the surface also accounts for fluorescing cells positioned deeper in the photic zone, which are actually exposed to lower light levels in their microhabitat.

The expected effect is a light-dependent overestimation of biofilm-level $\Delta F / F_{\mathrm{m}}$ ' relative to the inherent, physiological values of the cells at the surface, which is then expected to cause a systematic overestimation of $q_{\mathrm{E}}$ and underestimation of $q_{\mathrm{I}}$ (Serôdio 2004). However, besides this static effect, dynamic effects can also be expected. During prolonged exposure to high light, the downward migration of microalgae to less illuminated layers is likely to induce a gradual increase of $\Delta F / F_{\mathrm{m}}^{\prime}$ (as measured at the surface) independently of any photophysiological changes, thus causing the overestimation of $q_{\mathrm{E}}$. It is also conceivable that these types of effects may affect the measurement of $\Delta F / F_{\mathrm{m}}^{\prime}$ during the recovery under low light due to upward migration as a response to the decrease in incident irradiance. This, however, seems less likely due to the relatively short time of this period and to the fact that a transition from high to low light is a weaker stimulus for vertical migration, especially if the transition coincides with the end of the low tide period (Coelho et al. 2011).

A second factor that might explain the low values of $q_{\mathrm{I}}$ is the light doses applied during the light stress-recovery experiments in the laboratory. 
Because these doses $\left(3 \mathrm{~h}, 1200 \mu \mathrm{mol}\right.$ quanta $\left.\mathrm{m}^{-2} \mathrm{~s}^{-1}\right)$ were likely lower than the ones received during a typical period of exposure at low tide (up to 8-10 h, 1500-2000 umol quanta $\mathrm{m}^{-2} \mathrm{~s}^{-1}$ ), larger, but still ecologically relevant, light doses could have been applied that would likely induce larger cumulative photoinhibitory effects. The light exposure conditions applied in the present study, both regarding light intensity and duration, resulted from a compromise among inducing measurable effects, addressing instrument limitations (maximum PAR irradiance provided by the imaging fluorometer), and minimizing uncontrollable experimental conditions (excessive sample heating and desiccation caused by the fluorometer LED panel). Despite these limitations, mostly instrument-related, the laboratory experimental approach used in the present study has the advantage over studies carried out under in situ conditions (e.g. Serôdio et al. 2008, Perkins et al. 2010) of allowing the application of controlled and reproducible conditions, making it possible to directly compare the migratory and physiological responses of samples collected in different places and occasions.

The estimation of $q_{\mathrm{E}}$ and $q_{\mathrm{I}}$ is also directly affected by the type of analysis made of the recovery kinetics to distinguish the 2 components of NPQ. For higher plants, $q_{\mathrm{E}}$ and $q_{\mathrm{I}}$ are distinguished on the basis of the recovery rate of $F_{\mathrm{v}} / F_{\mathrm{m}}$, typically 10 to $15 \mathrm{~min}$, which is assumed to correspond to the full reversal of the xanthophyll cycle (Horton \& Hague 1988, Ruban \& Horton 1995). Following the common practice for the distinction of $q_{\mathrm{E}}$ and $q_{\mathrm{I}}$, in the present study, these 2 components of NPQ were estimated based on a relaxation time of the xanthophyll cycle of $10.5 \mathrm{~min}$. However, to evaluate the possible effects of considering different times for the reversal of the xanthophyll cycle on the relative magnitude of $q_{\mathrm{E}}$ and $q_{\mathrm{I}}$, a sensitivity analysis was performed consisting of the re-calculation of these estimates when considering 6 and $15 \mathrm{~min}$, values matching the range of relaxation times of the xanthophyll cycle expectable for diatoms (Goss et al. 2006, B. Lepetit \& J. Lavaud pers. obs.). The use of these different recovery periods did not alter significantly the general findings of the present study, including high levels of recovery and low photoinhibition rates, the increase in photoinhibition levels from May to October, and a relatively low $(<30 \%)$ combined contribution of vertical migration and xanthophyll cycle to overall photoprotection (Table 2). Nonetheless, this analysis shows some effects, although largely expected from the asymptotic pattern of $\Delta F / F_{\mathrm{m}}{ }^{\prime}$ recovery during the con- sidered period: the use of a shorter period resulted in the estimation of lower rates of recovery, leading to a likely overestimation of photoinhibition rates; conversely, longer periods resulted in larger rates of recovery and probably overestimated levels of photoprotection (Table 2). Moreover, due to the different relaxation patterns of samples exposed to different treatments, the evaluation of the relative importance of vertical migration and the xanthophyll cycle was also affected by the time period considered, with shorter and longer recovery periods resulting in a higher apparent contribution of vertical migration and of the xanthophyll cycle, respectively. These effects, however, did not substantially affect the overall pattern of variation of the role of the 2 photoprotective processes between the 2 sampling periods.

Recently, a more sophisticated method, based on the mathematical modeling and deconvolution of the recovery curve, was proposed to trace the recovery of each individual component of NPQ (Roháček 2010). This method could not be applied in the present study because of the particularities of the xanthophyll cycle in diatoms, which may not verify the assumptions of the method. First, diatoms lack $q_{\mathrm{T}}$ (the state-transition quenching) (Owens 1986, Lavaud 2007, Goss \& Jakob 2010), which called for the modification of this model to a 2-component NPQ. Second, it is impossible to use changes in $F_{\mathrm{v}} / F_{\mathrm{m}}$ in biofilms as an indication of photoinhibition because this requires the darkening of the samples, known to induce changes in $F_{\mathrm{m}}$ levels due to vertical migration. Furthermore, in benthic diatoms, dark adaptation often causes the $F_{\mathrm{m}}$ level to decrease to values below $F_{\mathrm{m}}$ ' levels measured under low light (Serôdio et al. 2006). These reasons also prevented the use of other recently proposed methods to quantify the components of NPQ (Ahn et al. 2009, Guadagno et al. 2010).

The formation of DT in the dark and thus anoxic subsurface layers of the sediment, known to occur in diatoms (Jakob et al. 2001) and especially in benthic assemblages (Serôdio et al. 2006), is a likely explanation for the apparent impossibility to completely eliminate NPQ by applying the xanthophyll cycle inhibitor DTT (Fig. 3). The DT thus formed would remain present despite the treatment with DTT, which prevents new conversion of DD to DT but does not induce the reversed reaction. Upon exposure to high light, the oxygenation of DT-rich subsurface layers would allow for the observed rise in NPQ, as the formation of NPQ from DT is known to be inhibited by anoxia (Cruz et al. 2011). 


\section{Photoprotection: vertical migration vs. xanthophyll cycle}

The use of specific inhibitors for vertical migration and for the operation of the xanthophyll cycle allowed estimation of the relative contribution of each of these processes to overall photoprotection of the biofilm. The results showed a change with season and photoacclimation state of their relative importance. While in May the 2 processes seemed to contribute similarly to biofilm photoprotection, the loss of photoprotection capacity from May to October was associated with a decrease in the contribution of the xanthophyll cycle, so that vertical migration became the dominant photoprotective process. The observed change in the species composition of the microphytobenthic assemblage may explain this difference because the activity of the xanthophyll cycle can differ among species (Lavaud et al. 2004, Goss et al. 2006). It may also be hypothesized that this difference is related to the decrease in rates of enzymatic conversion between DD and DT associated with photoacclimation or due to acclimation to lower temperatures (Van Leeuwe et al. 2008), an effect that is also species-related (Salleh \& McMinn 2011). Nevertheless, these results indicate that behavioral photoprotection seems able to maintain the overall photoprotection capacity, compensating for the decrease in the contribution of the xanthophyll cycle during the winter season.

The change in species composition, involving a dominance of larger cells in October, could also have affected the migratory response of the assemblages to high light. However, although some studies have shown a relation between migratory cell size and migratory behavior in sediments (Hay et al. 1993, Underwood et al. 2005), there is no evidence that cell size is an important factor regarding the migratory response to light stress. Also, the selective nature of the sampling method used may have resulted in an underestimation of the true variability in species composition at the surface.

Vertical migration and the xanthophyll cycle have been considered as the main photoprotective mechanisms in microphytobenthic biofilms (Serôdio et al. 2005, Jesus et al. 2006, Mouget et al. 2008, Serôdio et al. 2008, Perkins et al. 2010). A perhaps surprising result of the present study is the relatively low contribution of these 2 processes to overall photoprotection. This suggests the potential role of other processes responsible for the observed low rates of photoinhibition. Likely candidates include the cyclic electron flow around PSII (Lavaud et al. 2002b,
Lavaud 2007), the efficient scavenging of reactive oxygen species (Roncarati et al. 2008, Waring et al. 2010), or high turnover rates of the PSII protein D1 (Wu et al. 2011).

\section{Use of inhibitors on microphytobenthic biofilms}

An aim of the present study was the introduction of a new experimental protocol to estimate photoprotection efficiency and the extent of photoinhibition in microphytobenthic biofilms. This involved the combination of (1) the use of specific inhibitors for different photoprotective processes, applied alone and in combination with each other, allowing the estimation of the relative contribution of each process to overall photoprotection, and (2) the use of imaging fluorometry on replicated samples in well plates, taking advantage of the self-forming nature of microphytobenthic biofilms from homogenized sediments, which allowed for adequate replication and low variability among replicates and for the simultaneous testing of different treatments.

Some potential pitfalls exist regarding the use of inhibitors on biofilms and the interpretation of results. First, it must be noted that when comparing controls (no inhibitor added) with Lat A-treated samples, it is likely that the differences in fluorescence parameters observed over time may be attributed not only to changes in cell physiological conditions but also to changes in cell composition in the upper layers of the sediment. This is because in the controls, as opposed to Lat A-treated samples, cells initially at the surface likely migrated down into layers below the photic zone, therefore changing the contribution to the fluorescence signal measured at the surface. As a consequence, any observed differences are expected to represent mainly changes at the biofilm (i.e. community) level and not only changes in the physiology of individual cells. This also explains the need to combine Lat A and DTT if the effect of inhibiting the xanthophyll cycle is to be evaluated in the same microalgal assemblage. By adding DTT to samples treated with Lat A, it is ensured that the same cells remain in the photic zone of the sediment and that measured changes in fluorescence are due to changes in their physiological status and not to changes in community composition. If only DTT is applied (Perkins et al. 2010), only biofilm-level effects can be evaluated, as many cells will likely respond to high light by migrating downward and become unobservable (Oxborough et al. 2000). 
Acknowledgements. We thank Dr. C. Vincent and M. France and J. F. Breilh for providing solar radiation data and geographical data, respectively. The present study was supported by the Fundação para a Ciência e a Tecnologia through grants SFRH/BSAB/962/2009 (J.S.), SFRH/BD/ 44860/2008 (J.E.), and project MigROS (PTDC/MAR/ 112473/2009) and by the Centre National de la Recherche Scientifique ('chercheurs invités' program, J.S. and J.L.), the regional Charente-Maritime/CG17 (A.B. PhD grant), and by the French consortium CPER-Littoral. We thank 3 anonymous reviewers for their critical comments on the manuscript.

\section{LITERATURE CITED}

Admiraal W (1984) The ecology of estuarine sedimentinhabiting diatoms. Prog Phycol Res 3:269-322

- Ahn TK, Avenson TJ, Peers G, Li Z and others (2009) Investigating energy partitioning during photosynthesis using an expanded quantum yield convention. Chem Phys 357: 151-158

> Behrenfeld MJ, Prasil O, Babin M, Bruyant F (2004) In search of a physiological basis for covariations in lightlimited and light-saturated photosynthesis. J Phycol 40: $4-25$

Blanchard GF, Cariou-Le Gall V (1994) Photosynthetic characteristics of microphytobenthos in MarennesOléron Bay, France: preliminary results. J Exp Mar Biol Ecol 182:1-14

> Blanchard GF, Guarini JM, Gros P, Richard P (1997) Seasonal effect on the relationship between the photosynthetic capacity of intertidal microphytobenthos and temperature. J Phycol 33:723-728

Blanchard GF, Guarini JM, Dang C, Richard P (2004) Characterizing and quantifying photoinhibition in intertidal microphytobenthos. J Phycol 40:692-696

> Brotas V, Risgaard-Petersen N, Ottossen L, Serôdio J, Ribeiro L, Dalsgaard T (2003) In situ measurement of photosynthetic activity and respiration of intertidal benthic microalgal communities undergoing vertical migration. Ophelia 57:13-26

Brunet C, Lavaud J (2010) Can the xanthophyll cycle help extract the essence of the microalgal functional response to a variable light environment? J Plankton Res 32: 1609-1617

Cartaxana P, Serôdio J (2008) Inhibiting diatom motility: a new tool for the study of the photophysiology of intertidal microphytobenthic biofilms. Limnol Oceanogr Methods 6:466-476

> Cartaxana P, Brotas V, Serôdio J (2008) Effects of two motility inhibitors on the photosynthetic activity of the diatoms Cylindrotheca closterium and Pleurosigma angulatum. Diatom Res 23:65-74

> Cartaxana P, Ruivo M, Hubas C, Davidson I, Serôdio J, Jesus B (2011) Physiological versus behavioural photoprotection in intertidal epipelic and epipsamic benthic diatom communities. J Exp Mar Biol Ecol 405:120-127

> Chevalier EM, Gévaert F, Créach A (2010) In situ photosynthetic activity and xanthophylls cycle development of undisturbed microphytobenthos in an intertidal mudflat. J Exp Mar Biol Ecol 385:44-49

> Coelho H, Vieira S, Serôdio J (2009) Effects of desiccation on the photosynthetic activity of intertidal microphytobenthos biofilms as studied by optical methods. J Exp Mar
Biol Ecol 381:98-104

Coelho H, Vieira S, Serôdio J (2011) Endogenous versus environmental control of vertical migration by intertidal benthic microalgae. Eur J Phycol 46:271-281

> Consalvey M, Paterson DM, Underwood GJC (2004) The ups and downs of life in a benthic biofilm: migration of benthic diatoms. Diatom Res 19:181-202

> Cook PLM, Røy H (2006) Advective relief of $\mathrm{CO}_{2}$ limitation in microphytobenthos in highly productive sandy sediments. Limnol Oceanogr 51:1594-1601

Cruz S, Serôdio J (2008) Relationship of rapid light curves of variable fluorescence to photoacclimation and non-photochemical quenching in a benthic diatom. Aquat Bot 88: 256-264

> Cruz S, Goss R, Wilhelm C, Leegood R, Horton P, Jakob T (2011) Impact of chlororespiration on non-photochemical quenching of chlorophyll fluorescence and on the regulation of the diadinoxanthin cycle in the diatom Thalassiosira pseudonana. J Exp Bot 62:509-519

> Eilers PHC, Peeters JCH (1988) A model for the relationship between light intensity and the rate of photosynthesis in phytoplankton. Ecol Modell 42:199-215

Forster RM, Kromkamp JC (2004) Modelling the effects of chlorophyll fluorescence from subsurface layers on photosynthetic efficiency measurements in microphytobenthic algae. Mar Ecol Prog Ser 284:9-22

Genty B, Briantais JM, Baker NR (1989) The relationship between the quantum yield of photosynthetic electron transport and quenching of chlorophyll fluorescence. Biochim Biophys Acta 990:87-92

Goss R, Jakob T (2010) Regulation and function of xanthophyll cycle-dependent photoprotection in algae. Photosynth Res 106:103-122

Goss R, Pinto AE, Wilhelm C, Richter M (2006) The importance of a highly active and $\Delta \mathrm{pH}$-regulated diatoxanthin epoxidase for the regulation of the PS II antenna function in diadinoxanthin containing algae. J Plant Physiol 163: 1008-1021

Guadagno CR, Virzo De Santo A, D'Ambrosio N (2010) A revised energy partitioning approach to assess the yields of non-photochemical quenching components. Biochim Biophys Acta 1797:525-530

Hay SI, Maitland TC, Paterson DM (1993) The speed of diatom migration through natural and artificial substrata. Diatom Res 8:371-384

> Henley WJ (1993) Measurement and interpretation of photosynthetic light-response curves in algae in the context of photoinhibition and diel changes. J Phycol 29:729-739

Herlory O, Guarini JM, Richard P, Blanchard GF (2004) Microstructure of microphytobenthic biofilm and its spatio-temporal dynamics in an intertidal mudflat (Aiguillon Bay, France). Mar Ecol Prog Ser 282:33-44

> Horton P, Hague A (1988) Studies on the induction of chlorophyll fluorescence in isolated barley protoplasts. 4 . Resolution of non-photochemical quenching. Biochim Biophys Acta 932:107-115

Jakob T, Goss R, Wilhelm C (2001) Unusual pH-dependence of diadinoxanthin de-epoxidase activation causes chlororespiratory induced accumulation of diatoxanthin in the diatom Phaeodactylum tricornutum. J Plant Physiol 158: 383-390

- Jesus B, Perkins RG, Consalvey M, Brotas V, Paterson DM (2006) Effects of vertical migrations by benthic microalgae on fluorescence measurements of photophysiology. Mar Ecol Prog Ser 315:55-66 
Jordan L, McMinn A, Thompson P (2010) Diurnal changes of photoadaptive pigments in microphytobenthos. J Mar Biol Assoc UK 90:1025-1032

Kromkamp J, Barranguet C, Peene J (1998) Determination of microphytobenthos PSII quantum efficiency and photosynthetic activity by means of variable chlorophyll fluorescence. Mar Ecol Prog Ser 162:45-55

Lavaud J (2007) Fast regulation of photosynthesis in diatoms: mechanisms, evolution and ecophysiology. Funct Plant Sci Biotechnol 1:267-287

Lavaud J, Rousseau B, Etienne AL (2002a) In diatoms, a transthylakoidal proton gradient alone is not sufficient to induce a non-photochemical fluorescence quenching. FEBS Lett 523:163-166

Lavaud J, Gorkom HJV, Etienne AL (2002b) Photosystem II electron transfer cycle and chlororespiration in planktonic diatoms. Photosynth Res 74:51-59

> Lavaud J, Rousseau B, Etienne AL (2004) General features of photoprotection by energy dissipation in planktonic diatoms (Bacillariophyceae). J Phycol 40: 130-137

> MacIntyre HL, Kana TM, Anning T, Geider RJ (2002) Photoacclimation of photosynthesis irradiance response curves and photosynthetic pigments in microalgae and cyanobacteria. J Phycol 38:17-38

Méléder V, Rincé Y, Barillé L, Gaudin P, Rosa P (2007) Spatio-temporal changes in microphytobenthos assemblages in a macrotidal flat (Bourgneuf Bay, France). J Phycol 43: $1177-1190$

> Migné A, Spilmont N, Davoult D (2004) In situ measurements of benthic primary production during emersion: seasonal variations and annual production in the Bay of Somme (eastern English Channel, France). Cont Shelf Res 24:1437-1449

Miles A, Sundbäck K (2000) Diel variation in microphytobenthic productivity in areas of different tidal amplitude. Mar Ecol Prog Ser 205:11-22

> Mouget JL, Perkins R, Consalvey M, Lefebvre S (2008) Migration or photoacclimation to prevent high irradiance and UV-B damage in marine microphytobenthic communities. Aquat Microb Ecol 52:223-232

Müller P, Li XP, Niyogi KK (2001) Non-photochemical quenching. A response to excess light energy. Plant Physiol 125:1558-1566

> Nishiyama Y, Allakhverdiev SI, Murata N (2006) A new paradigm for the action of reactive oxygen species in the photoinhibition of photosystem II. Biochim Biophys Acta 1757:742-749

Olaizola M, Yamamoto HY (1994) Short-term response of the diadinoxanthin cycle and fluorescence yield to high irradiance in Chaetoceros muelleri (Bacillariophyceae). J Phycol 30:606-612

>wens TG (1986) Light-harvesting function in the diatom Phaeodactylum tricornutum II. Distribution of excitation energy between the photosystems. Plant Physiol 80: 732-738

Oxborough K, Hanlon ARM, Underwood GJC, Baker NR (2000) In vivo estimation of the photosystem II photochemical efficiency of individual microphytobenthic cells using high-resolution imaging of chlorophyll a fluorescence. Limnol Oceanogr 45:1420-1425

Perkins RG, Mouget JL, Lefebvre S, Lavaud J (2006) Light response curve methodology and possible implications in the application of chlorophyll fluorescence to benthic diatoms. Mar Biol 149:703-712
Perkins RG, Kromkamp J, Serôdio J, Lavaud J and others (2010a) The application of variable chlorophyll fluorescence to microphytobenthic biofilms. In: Sugget D, Prasil O, Borowitzka MA (eds) Chlorophyll a fluorescence in aquatic sciences: methods and applications, Series: developments in applied phycology, Vol 4. Springer, Dordrecht, p 237-276

Perkins RG, Lavaud J, Serôdio J, Mouget JL and others (2010b) Vertical cell movement is the primary response of intertidal benthic biofilms to increasing light dose. Mar Ecol Prog Ser 416:93-103

Ribeiro L (2010) Intertidal benthic diatoms of the Tagus estuary: taxonomic composition and spatial-temporal variation. PhD thesis, University of Lisbon

> Rijstenbil JW (2005) UV- and salinity-induced oxidative effects in the marine diatom Cylindrotheca closterium during simulated emersion. Mar Biol 147:1063-1073

Ritchie RJ (2008) Fitting light saturation curves measured using modulated fluorometry. Photosynth Res 96: 201-215

Roháček K (2010) Method for resolution and quantification of components of the non-photochemical quenching $\left(q_{\mathrm{N}}\right)$. Photosynth Res 105:101-113

Roncarati F, Rijstenbil JW, Pistocchi R (2008) Photosynthetic performance, oxidative damage and antioxidants in Cylindrotheca closterium in response to high irradiance, UVB radiation and salinity. Mar Biol 153:965-973

Ruban AV, Horton (1995) An investigation of the sustained component of nonphotochemical quenching of chlorophyll fluorescence in isolated chloroplasts and leaves of spinach. Plant Physiol 108:721-726

Salleh S, McMinn A (2011) The effects of temperature on the photosynthetic parameters and recovery of two temperate benthic microalgae, Amphora cf. coffeaeformis and Cocconeis cf. sublittoralis (Bacillariophyceae). J Phycol 47:1413-1424

Schumann A, Goss R, Jakob T, Wilhelm C (2007) Investigations on the quenching efficiency of diatoxanthin in cells of Phaeodactylum tricornutum (Bacillariophyceae) with different pool sizes of xanthophyll cycle pigments. Phycologia 46:113-117

Serôdio J (2004) Analysis of variable chlorophyll fluorescence in microphytobenthos assemblages: implications of the use of depth-integrated measurements. Aquat Microb Ecol 36:137-152

Serôdio J, Catarino F (1999) Fortnightly light and temperature variability on estuarine intertidal sediments and implications for microphytobenthos primary productivity. Aquat Ecol 33:235-241

Serôdio J, Lavaud J (2011) A model for describing the light response of the non-photochemical quenching of chlorophyll fluorescence. Photosynth Res 108:61-76

Serôdio J, Cruz S, Vieira S, Brotas V (2005) Non-photochemical quenching of chlorophyll fluorescence and operation of the xanthophyll cycle in estuarine microphytobenthos. J Exp Mar Biol Ecol 326:157-169

Serôdio J, Vieira S, Cruz S, Coelho H (2006) Rapid lightresponse curves of chlorophyll fluorescence in microalgae: relationship to steady-state light curves and nonphotochemical quenching in benthic diatom-dominated assemblages. Photosynth Res 90:29-43

Serôdio J, Vieira S, Cruz S (2008) Photosynthetic activity, photoprotection and photoinhibition in intertidal microphytobenthos as studied in situ using variable chlorophyll fluorescence. Cont Shelf Res 28:1363-1375 
Underwood GJC (2002) Adaptations of tropical marine microphytobenthic assemblages along a gradient of light and nutrient availability in Suva Lagoon, Fiji. Eur J Phycol 37:449-462

Underwood GJC, Kromkamp J (1999) Primary production by phytoplankton and microphytobenthos in estuaries. Adv Ecol Res 29:93-153

Underwood GJC, Nilsson C, Sundbäck K, Wulff A (1999) Short-term effects of UVB radiation on chlorophyll fluorescence, biomass, pigments, and carbohydrate fractions in a benthic diatom mat. J Phycol 35:656-666

Underwood GJC, Perkins RG, Consalvey MC, Hanlon ARM, Oxborough K, Baker NR, Paterson DM (2005) Patterns in microphytobenthic primary productivity: species-specific variation in migratory rhythms and photosynthetic efficiency in mixed-species biofilms. Limnol Oceanogr 50:755-767

Van Leeuwe MA, Brotas V, Consalvey M, Forster RM and others (2008) Photoacclimation in microphytobenthos and the role of xanthophyll pigments. Eur J Phycol 43:

Editorial responsibility: Rutger de Wit, Montpellier, France
123-132

> Walters RG, Horton P (1991) Resolution of components of non-photochemical chlorophyll fluorescence quenching in barley leaves. Photosynth Res 27:121-133

Waring J, Baker NR, Underwood GJC (2007) Responses of estuarine intertidal microphytobenthic algal assemblages to enhanced ultraviolet $\mathrm{B}$ radiation. Glob Change Biol 13:1398-1413

Waring J, Klenell M, Bechtold U, Underwood GJC, Baker NR (2010) Light-induced responses of oxygen photoreduction, reactive oxygen species production and scavenging in two diatom species. J Phycol 46:1206-1217

Wu H, Cockshutt AM, McCarthy A, Campbell DA (2011) Distinctive photosystem II photoinactivation and protein dynamics in marine diatoms. Plant Physiol 156: 2184-2195

Wulff A, Roleda MY, Zacher K, Wiencke C (2008) UV radiation effects on pigments, photosynthetic efficiency and DNA of a semi-natural Antarctic marine benthic diatom community. Aquat Biol 3:167-177

Submitted: January 17, 2012; Accepted: July 30, 2012

Proofs received from author(s): September 30, 2012 